\title{
Founder of modern hydrocephalus diagnosis and therapy: Walter Dandy at the Johns Hopkins Hospital
}

\author{
Ari M. Blitz, MD, ${ }^{1}$ A. Karim Ahmed, BS, ${ }^{2}$ and Daniele Rigamonti, MD ${ }^{2,3}$ \\ Departments of ${ }^{1}$ Radiology and Radiologic Sciences and ${ }^{2}$ Neurosurgery, Johns Hopkins Hospital; and ${ }^{3}$ Johns Hopkins Aramco \\ Healthcare, Baltimore, Maryland
}

\begin{abstract}
Because of his exceptional and pioneering contributions to the understanding and treatment of neurosurgical conditions, Walter Dandy is considered to be one of the founders of both neurosurgery and neuroradiology. In the field of hydrocephalus, Dandy developed revolutionary research models, imaging modalities, and operative procedures. His laboratory and clinical experiences at the Johns Hopkins Hospital, including the surgical treatment of hydrocephalus, are well illustrated in the publications he authored. Archival materials housed at the Johns Hopkins University School of Medicine provide a window into Dandy's clinical experience and supplement the work published during his lifetime. His operative experience with hydrocephalus spanned 1915-1946 and comprised 381 surgeries. From this clinical experience, Dandy created much of the framework for modern diagnostic imaging and treatment of hydrocephalus.
\end{abstract}

https://thejns.org/doi/abs/10.3171/2018.4.JNS172316

KEYWORDS hydrocephalus; medical history; Walter Dandy; Johns Hopkins Hospital

$\mathrm{W}$ ALTER Dandy was one of the preeminent neurosurgeons of the twentieth century. His work on the pathophysiology and treatment of hydrocephalus $2,5,7,9,10$ paved the way for our understanding of cerebrospinal fluid (CSF) flow and its disorders. Dandy developed ventriculography and pneumoencephalography, the first means of visualizing the brain in a living patient. ${ }^{3,9,22}$ These groundbreaking neuroradiological methods used air to replace CSF, creating contrast between the brain and normally fluid-filled spaces of the ventricles and subarachnoid space., ${ }^{9,22}$ Dandy first detailed the subtypes of hydrocephalus in 1918 and introduced the surgical technique of choroid plexus removal for hydrocephalus treatment. ${ }^{6}$ His papers, housed in The Alan Mason Chesney Medical Archives of the Johns Hopkins University, include surgical case logs with a brief description of each case and supplement his written reports. The current paper highlights Dandy's revolutionary work in the identification, diagnosis, classification, and treatment of hydrocephalus, describing the clinical experiences that spurred his investigations.

\section{Methods}

After receiving IRB approval, we performed a retrospective review of Walter Dandy's archival material housed at The Alan Mason Chesney Medical Archives of the Johns Hopkins University as well as published articles pertaining to hydrocephalus. The number of operations per year and the type of operation performed, as well as Dandy's classification of the etiology of hydrocephalus, were recorded from his case logs. This information was correlated with Dandy's hydrocephalus-related contributions in the literature.

\section{Results}

\section{CSF Flow and Obstruction}

Dandy and co-resident Dr. Kenneth Blackfan published a seminal paper in December $1913,{ }^{10}$ the first of its kind in describing the circulation and absorption of CSF in obstructive hydrocephalus. Dandy and Blackfan successfully obstructed the aqueduct of Sylvius in a canine model by deploying a piece of cotton housed in a small gelatin capsule (Fig. 1). The symptoms that followed, primarily lethargy and vomiting, replicated the clinical condition. In addition, Dandy and Blackfan observed that a suspension of fine granules injected into the subarachnoid space did not freely pass into the blood. Thus, Dandy was the first to observe that CSF produced in the lateral ventricles is not adequately absorbed at that location and that CSF does not 
freely diffuse into the venous sinuses. In additional canine experiments involving the injection of phenolsulfonphthalein or any inert colored solution into the lateral ventricles and subsequent lumbar puncture drainage, he was able to demonstrate the role of the cortical subarachnoid space in the absorption of CSF produced in the ventricles. ${ }^{5}$ In his textbook The Brain, Dandy described the source of CSF: "If the choroid plexus is completely extirpated from a lateral ventricle and at the same time the foramen of Monro is occluded by a transplant of fascia, the ventricle will not enlarge. Cerebrospinal fluid, therefore, is derived from the choroid plexus and not the ependymal.", 1,3

In addition to ventricular obstruction, Dandy elucidated the mechanisms of hydrocephalus due to cisternal obstruction. In his chapter on hydrocephalus, ${ }^{1}$ he stated, "the obstructions which, although evident enough to the naked eye, might be questioned are in the cisternae. These can be demonstrated very simply and graphically by introducing India ink into the spinal canal of the cadaver and lowering the head precisely as shown in the results of the experiments on dogs. The ink will gravitate to and sharply define the obstruction."

\section{Classification of Hydrocephalus Subtypes}

Dandy described the two key pathophysiological mechanisms for the development of hydrocephalus: diminished absorption or increased production of $\mathrm{CSF}^{6}{ }^{6}$ The diminished absorption category consisted of communicating hydrocephalus (due to impaired reabsorption, i.e., adhesions in the subarachnoid space), obstructive hydrocephalus (congenital atresias, adhesions, tumors), and external hydrocephalus. Dandy acknowledged the category of increased CSF production but described it as very rare, pointing to hypertrophy of the choroid plexus-perhaps true choroid plexus hypertrophy or what we would now call "choroid plexus papilloma"-as a cause. Surgery for obstructive hydrocephalus was noted in Dandy's case logs for the first time on January 21, 1915. Extirpation for communicating hydrocephalus was first noted on February 6, 1918.

In his chapter and paper on hydrocephalus, ${ }^{1,6}$ Dandy noted that it was possible to "find at necropsy the lesion in every case of hydrocephalus" and to "reproduce experimentally in animals every kind of hydrocephalus" in order to determine a "rational method of treatment." He characterized hydrocephalus based on the location of occlusion after the injection of gas on cerebral pneumography (including direct-puncture ventriculography and pneumoencephalography where air is injected via the lumbar route). When gas would pass between the ventricular system and subarachnoid space, he used the term "communicating hydrocephalus"; when it would not pass, he used the term "noncommunicating hydrocephalus." In either case he presumed a site of obstruction to CSF movement, describing the following potential sites of obstruction:

Obstructions in a ventricle: "Only tumors and other spaceoccupying lesions are large enough to obstruct a lateral ventricle."

Obstructions of the interventricular foramen (Monro): "Most occlusions of this foramen are due to tumors."

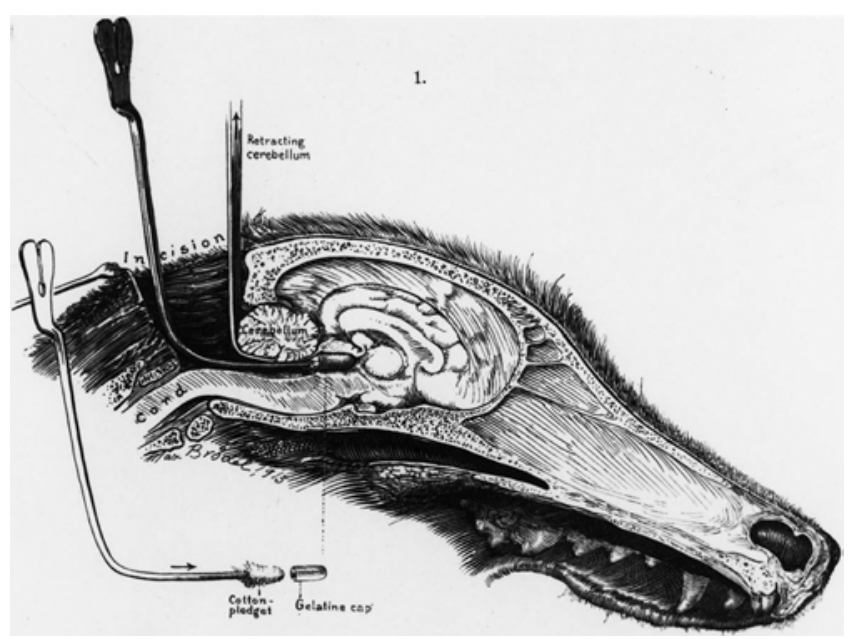

FIG. 1. Drs. Dandy and Blackfan successfully obstructed the aqueduct of Sylvius in a canine model by deploying a piece of cotton housed in a small gelatin capsule. Courtesy of The Alan Mason Chesney Medical Archives of The Johns Hopkins Medical Institutions.

Obstructions at the aqueduct of Sylvius: "In infants these obstructions are usually of congenital origin, atresia. . . . From stenosis of the aqueduct, an extensive cicatrix may fill the contiguous region of the mid-brain, even to the degree of suggesting a tumor. Similar strictures are not uncommon in adult life. ... . Cases in which the iter [aqueduct of Sylvius] is sealed by an inflammatory process are not uncommon. A cicatrix may also follow the removal of tumors. A cicatrix may also follow the removal of tumors of the third ventricle if the ependymal is injured."

Occlusions of the foramina of Luschka and Magendie:

"Tumors in the fourth ventricle are the most common causes after the first few months of life."

Obstructions in the cisternae: "Congenital occlusions in the cisternae are of two types: (1) Generalized absence of the cisternae, the meninges being tightly in apposition with the ventral surface of the brain stem. At times the meninges are delicate, at other times densely matted. Adhesions between the dura and brain stem are not uncommon. (2) At other times there is a transverse band across the ventral surface of the brain stem, usually at the midbrain. The cisternae are greatly dilated up to this obstruction which represents the most anterior part of the cisternae that has opened during fetal life."

\section{Operative Records of Hydrocephalus Cases at Hopkins}

Walter Dandy arrived at Johns Hopkins in 1907 as a second year medical student. There he would spend the remainder of his career. He performed his first operation on a patient with hydrocephalus in January 1915 and his last in 1946. Excerpts from his case logs, as well as the nurse's notebook detailing operative requirements, are featured in Figs. 2 and 3. Dandy performed a median of 11.5 cases per year (range 1-25) for the treatment of hydrocephalus. During his career, he brought patients to the operating room 381 times for the surgical treatment of hydrocephalus (Figs. 4-6).

Dandy's operative log points to an early interest in hydrocephalus classification. The second patient he operated on for hydrocephalus, in January 1915, was noted as hav- 


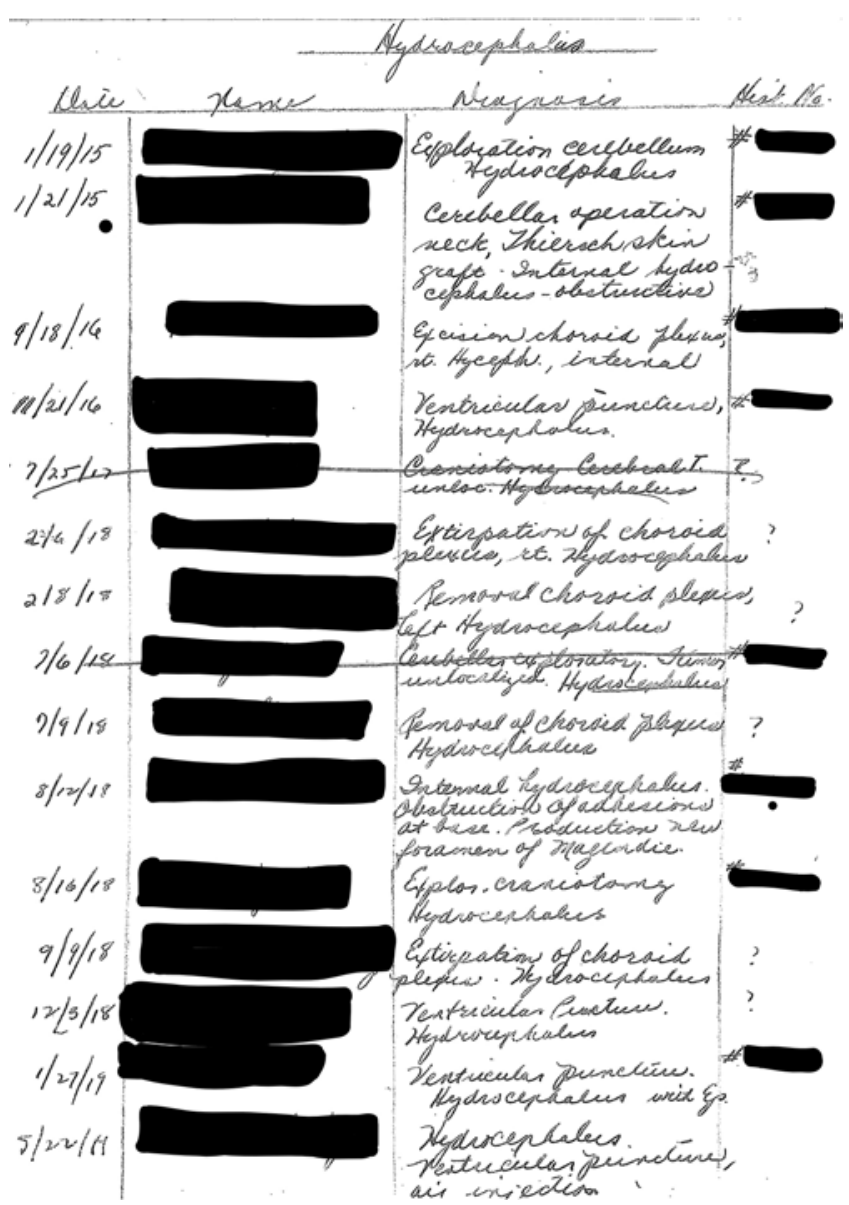

FIG. 2. The first page of Dandy's case log, 1915, at the Johns Hopkins Hospital. Courtesy of The Alan Mason Chesney Medical Archives of The Johns Hopkins Medical Institutions.

ing "internal hydrocephalus-obstructive" (Fig. 2). He first performed choroid plexus excision for the treatment of hydrocephalus in September 1916 in only his third patient with the diagnosis. In 1918 he wrote about this approach: "the plexus is then transected and gently stripped backward from its narrow attachment to the floor of the body of the ventricle. When the glomus is reached the stripping from the body of the ventricle is stopped and the choroid plexus is picked up at the tip of the descending horn." ${ }^{\circ}$ For his fourth patient with hydrocephalus, in November 1916, Dandy invented direct-puncture ventriculography (Fig. 2).

In his 17th surgery for hydrocephalus in 1920, Dandy first notes that "removal of the floor of the 3rd ventricle" was performed. In 1922 Dandy published details of the third ventriculostomy alongside those for the first endoscopic operative procedure for choroid plexectomy. ${ }^{7,19}$ In his description of cerebral ventriculoscopy, he notes, "on two occasions, it has seemed advisable to inspect a lateral ventricle. This was done in one instance through a small cytoscope and in a second an attempt was made with the help of a small operating ventriculoscope to remove and fulgurate the choroid plexus." In a subsequent article, Dandy notes, "a procedure which apparently is anatomically correct has been devised, to supersede any direct attack on the aqueduct. This consists in removing the floor

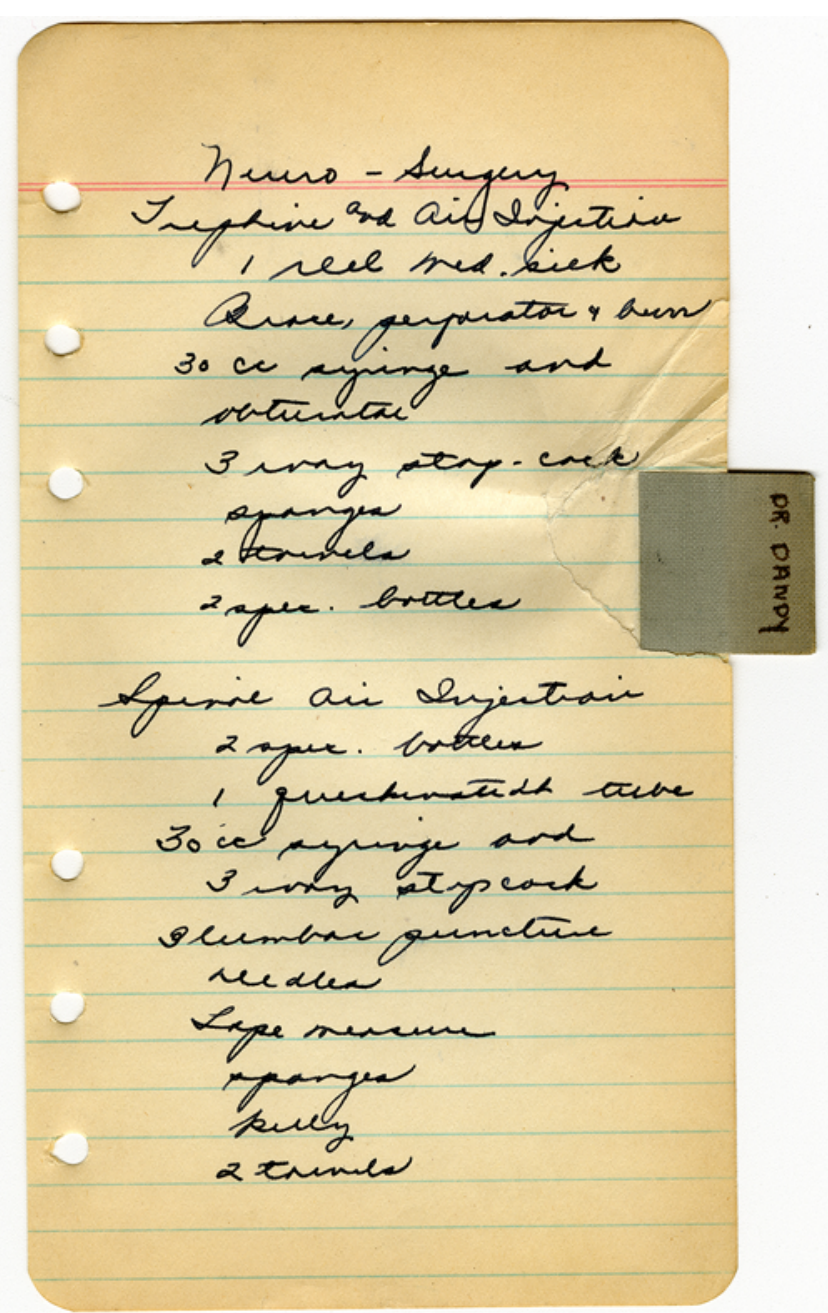

FIG. 3. Nurse's notebook page detailing the operating room equipment requirements for Dandy's cases. The cases, "Trephine and Air Injection" and "Spine Air Injection," describe air ventriculography and pneumoencephalography, respectively. Courtesy of The Alan Mason Chesney Medical Archives of The Johns Hopkins Medical Institutions. Figure is available in color online only.

of the third ventricle." The endoscopic approach and CSF diversion into the basal cisterns via the third ventricle would eventually provide the groundwork for the modern endoscopic third ventriculostomy (ETV)., 4,8,19 According to his case logs, Dandy performed many choroid plexectomies throughout his career, but the frequency of this procedure decreased over time because of poor visualization and surgical morbidity.

In 1921 Dandy described the operative treatment of hydrocephalus caused by occlusion of the foramina of Luschka and Magendie. ${ }^{3}$ In his paper, he describes a series of cases in which he successfully constructs a "new foramen of Magendie" for the first time. Among the various causes of occlusion are intrauterine inflammation in infants and a dense scar in adults.

The classification of cases as communicating and noncommunicating hydrocephalus, which we know today, was evidently taking shape by 1923 . In describing his 71st surgery in March 1923, the term "communicating hydro- 


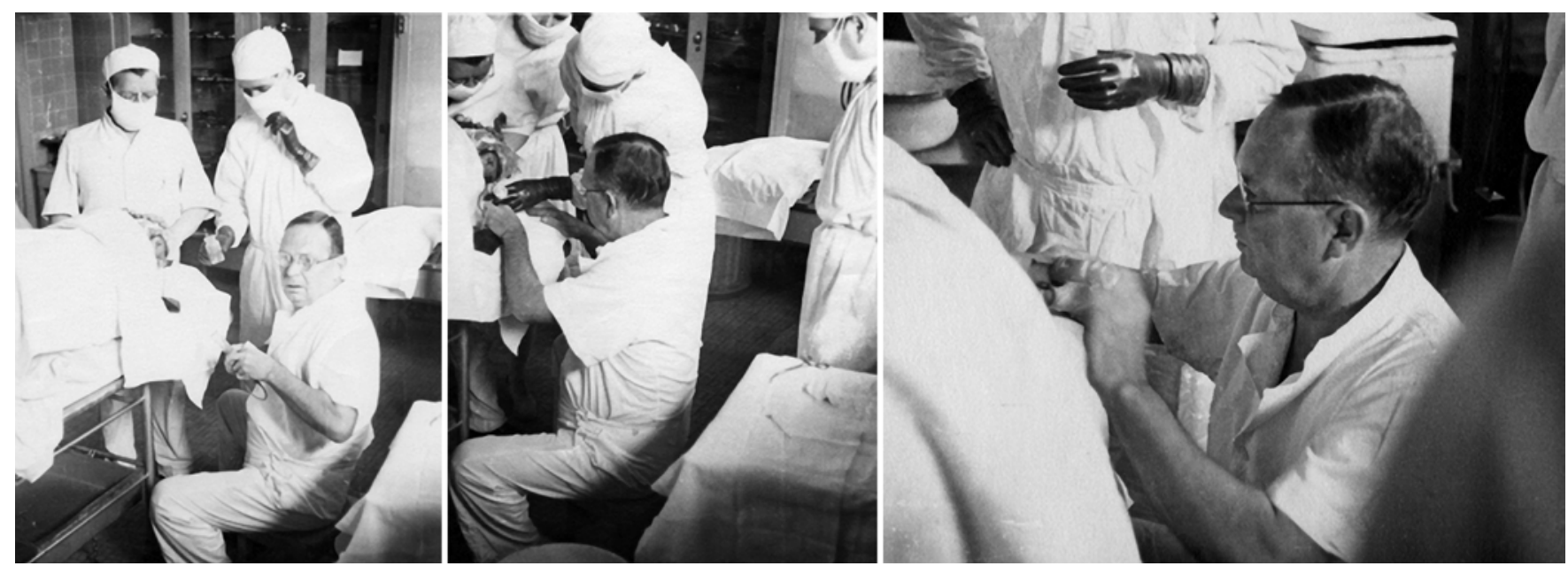

FIG. 4. Dandy and his surgical team performing ventriculography, 1946. Courtesy of The Alan Mason Chesney Medical Archives of The Johns Hopkins Medical Institutions.

cephalus" was used for the first time. For his 81st patient in November 1923, the term "noncommunicating hydrocephalus" was first used, although cases simply labeled as "obstructive hydrocephalus" continue to be noted subsequently.

Dandy's personal record of his operative cases informed his classification system, as cases were classified as communicating or noncommunicating or on the basis of the site of obstruction of CSF flow (e.g., stenosis of the cerebral aqueduct, "diffuse scar of the foramen of Magendie"). In his paper on idiopathic hydrocephalus, Dandy describes "communicating hydrocephalus, i.e., of that type of hydrocephalus in which all the ventricles are in communication with the subarachnoid space. In the course of intensive studies on the absorption of the CSF in hydrocephalus it was found that in the communicating type the absorption from the subarachnoid space was greatly reduced." 2

According to his case logs, the final operation for hydrocephalus in Dandy's career was a choroid plexectomy in 1946. Cases of obstructive hydrocephalus attributed to brain tumors were recorded in a separate log, with only 9 cases classified in this manner: 1 case each in 1917, 1918, 1922, and 1926; 2 cases in 1927; and 1 case each in 1932, 1939, and 1942.

\section{Global Acceptance and Evolution of Dandy's Hydrocephalus Contributions}

Walter Dandy introduced bilateral choroid plexectomy in 1918, which soon became the most common procedure for the treatment of infantile hydrocephalus in the country. ${ }^{6,13}$ Notwithstanding limited visualization and morbidity, the original operative technique was widely performed until 1942-1943, replaced by Scarff ${ }^{21}$ and Putnam's ${ }^{17}$ modified endoscopic approach. Bilateral choroid plexectomy is occasionally performed to treat excess CSF production and has recently been applied for the management of other disease processes. Nimjee et al. described a case of choroid plexus papilloma successfully treated with bilateral plexectomy. ${ }^{15}$ In addition, bilateral plexectomy may be a viable alternative to CSF diversion for pediatric patients with hydranencephaly-reducing the financial burden, readmissions, reoperations, length of hospitalization, and complications associated with CSF diversion. ${ }^{23}$

In an effort to treat hydrocephalus due to aqueductal stenosis, Dandy pioneered the operative technique of third ventriculostomy, bypassing the site of obstruction for the interpedicular cistern. ${ }^{15}$

Dandy's distinction between obstructive and nonobstructive hydrocephalus, based on the presence of intraventricular dye recovered on lumbar puncture, was undoubtedly groundbreaking, but it was not sufficient in describing the spectrum and underlying pathophysiology of the condition..$^{20}$ In 1960 Ransohoff et al. ${ }^{18}$ updated Dandy's classification, identifying additional sites for potential obstruction, including scarred cortical subarachnoid spaces (i.e., arachnoid villi).

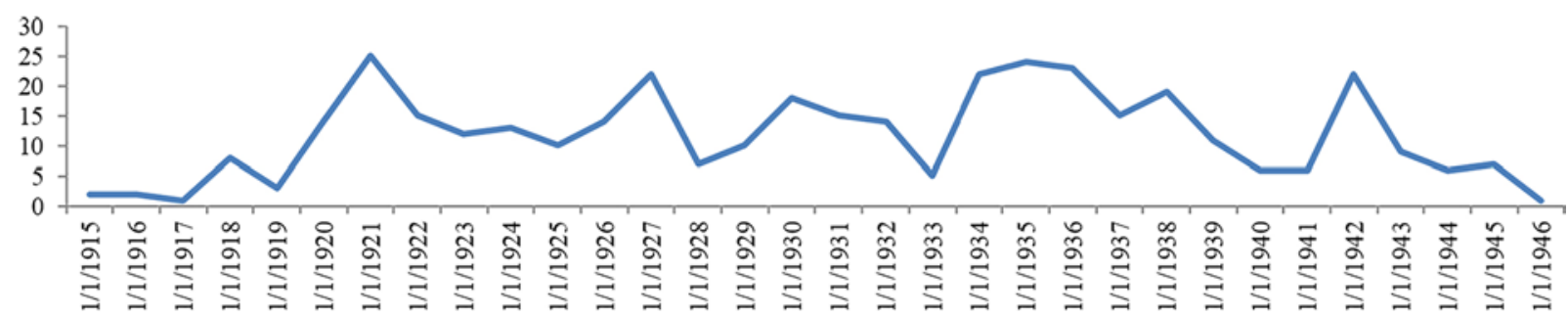

FIG. 5. Dandy's hydrocephalus cases per year at the Johns Hopkins Hospital from 1915 to 1946. The y-axis indicates the number of cases per year. Figure is available in color online only. 


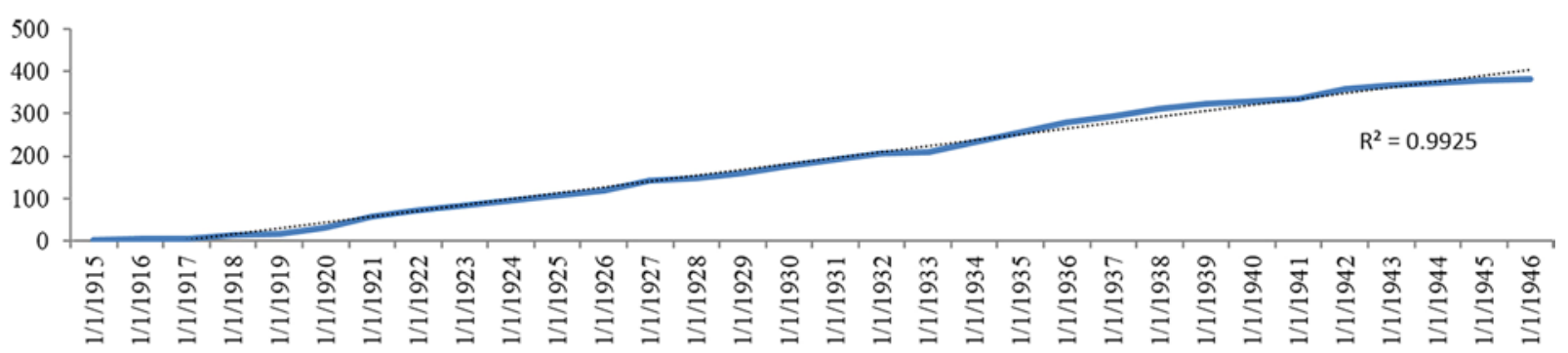

FIG. 6. Dandy's cumulative operative experience from 1915 to 1946 for the treatment of hydrocephalus. The y-axis indicates the cumulative number of cases. Figure is available in color online only.

\section{Discussion}

The study of CSF was a relatively new development during Dandy's training. Quincke had described lumbar puncture in 1891, and Froin and Nonne described the syndrome of CSF obstruction or compression in 1903 and 1907, respectively. ${ }^{11,12,14}$ A case of spontaneous air encephalography was described by Luckett and Stewart in 1912/1913. ${ }^{12}$ Lewis H. Weed initially demonstrated CSF formation in the choroid plexus and its exit from the fourth ventricle into the subarachnoid space, a finding confirmed by Dandy and Blackfan, who obstructed the cerebral aqueduct. ${ }^{10}$ Dandy was a pioneer in many aspects of neurosurgery and neuroradiology and extended the work of earlier investigators. His contributions to the understanding of hydrocephalus, imaging, and operative techniques not only were novel for the time, but also provided much of the framework for current management.

Through his canine studies, ventriculography, and pneumoencephalography, Dandy was able to shed light on patterns of CSF flow between the ventricles, subarachnoid spaces, and major areas of occlusion. This understanding of hydrocephalus endowed Dandy with the tools to develop innovative procedures for the treatment of hydrocephalus, thus paving the way for modern operative approaches. His surgical notes describe in detail the findings in 381 patients surgically treated for hydrocephalus of diverse etiologies throughout his career.

His contributions are the fruit of an exceptional mind that, starting from clinical observations, developed laboratory models recapitulating the human conditions and imaging modalities that greatly improved his ability to confirm diagnoses in preparation for the curative surgical intervention. Interestingly, many of Dandy's illustrations, including the one presented in Fig. 1, were completed by Max Brödel, considered the father of modern medical illustration. ${ }^{16}$

To our knowledge, this is the first work to chronicle Dandy's hydrocephalus-related academic work, innovative surgical techniques, and operative case logs; the public acceptance of CSF production; and the evolution in our understanding of hydrocephalus to the modern day. Although Dandy's contributions to the field of hydrocephalus are historically known, little work has been done to describe the advancement of his ideas over his lifetime relative to his published animal experiments and operative case logs. The current work provides a unique view into Dandy's life through the timeline of his academic and clinical activities to further our understanding of hydrocephalus. Never be- fore published, Dandy's hydrocephalus case logs illustrate his impressive productivity as a surgeon and his bench-tobedside approach as a scientist.

\section{Conclusions}

Walter Dandy's early clinical experiences were critical in shaping our field. He invented direct-puncture ventriculography, the predecessor of modern neuroradiological examination, and developed a reasoned approach to hydrocephalus treatment based on the site of CSF obstruction. He also developed third ventriculostomy to allow for the bypass of fluid from the ventricular system to the subarachnoid space. Reviewing the variety of case material and the evolution of knowledge during the span of his career provides insight into how much the genius of this man contributed to our understanding of CSF diseases and hydrocephalus.

\section{Acknowledgments}

We wish to acknowledge the contributions of Dr. David Solomon, without whose friendship and collaboration this work either would never have come to pass or would certainly have lacked the pleasure we shared in exploring the medical archives of the Johns Hopkins University School of Medicine. His passing has come unexpectedly and far too soon. We also wish to acknowledge the expert assistance of the staff at The Alan Mason Chesney Archives of the Johns Hopkins University, without whose aid the archival materials featured would not have seen the light of day.

\section{References}

1. Dandy WE: The Brain. New York: Joanna Cotler Books, 1970

2. Dandy WE: The cause of so-called idiopathic hydrocephalus. Bull Johns Hopkins Hosp 361:67-75, 1921

3. Dandy WE: The diagnosis and treatment of hydrocephalus due to occlusions of the foramina of Magendie and Luschka. Surg Gynecol Obstet 32:112-124, 1921

4. Dandy WE: The diagnosis and treatment of hydrocephalus resulting from strictures of the aqueduct of Sylvius. Surg Gynecol Obstet 31:340-358, 1920

5. Dandy WE: Experimental hydrocephalus. Ann Surg 70:129-142, 1919

6. Dandy WE: Extirpation of the choroid plexus of the lateral ventricles in communicating hydrocephalus. Ann Surg 68:569-579, 1918

7. Dandy WE: An operative procedure for hydrocephalus. Bull Johns Hopkins Hosp 33:189-190, 1922

8. Dandy WE: The operative treatment of communicating hydrocephalus. Ann Surg 108:194-202, 1938 
9. Dandy WE: Ventriculography following injection of air into the cerebral ventricles. Ann Surg 68:5-11, 1918

10. Dandy WE, Blackfan KD: An experimental and clinical study of internal hydrocephalus. JAMA 61:2216-2217, 1913

11. Haymaker W, Schiller F: The Founders of Neurology. Springfield, IL: Charles C. Thomas, 1970

12. Kautzky R, Zülch KJ, Wende S, Tänzer A: Neuroradiology: A Neuropathological Approach. Berlin: Springer, 1982

13. Lifshutz JI, Johnson WD: History of hydrocephalus and its treatments. Neurosurg Focus 11(2):E1, 2001

14. McHenry LC Jr, Garrison FH: Garrison's History of Neurology. Springfield, IL: Charles C. Thomas, 1969

15. Nimjee SM, Powers CJ, McLendon RE, Grant GA, Fuchs HE: Single-stage bilateral choroid plexectomy for choroid plexus papilloma in a patient presenting with high cerebrospinal fluid output. J Neurosurg Pediatr 5:342-345, 2010

16. Patel SK, Couldwell WT, Liu JK: Max Brödel: his art, legacy, and contributions to neurosurgery through medical illustration. J Neurosurg 115:182-190, 2011

17. Putnam T: Surgical treatment of infantile hydrocephalus. Surg Gynecol Obstet 76:171-182, 1943

18. Ransohoff J, Shulman K, Fishman RA: Hydrocephalus: a review of etiology and treatment. J Pediatr 56:399-411, 1960

19. Recinos PF, Jallo GI, Recinos VR: Endoscopic third ventriculostomy, in Quiñones-Hinojosa A (ed): Schmidek and Sweet: Operative Neurosurgical Techniques: Indications, Methods, and Results. Philadelphia: Elsevier Saunders, 2012

20. Rekate HL: The definition and classification of hydrocephalus: a personal recommendation to stimulate debate. Cerebrospinal Fluid Res 5:2, 2008

21. Scarff JE: Nonobstructive hydrocephalus. Treatment by endoscopic cauterization of the choroid plexus. Am J Dis Child 63:297-334, 1942
22. Tondreau RL: Ventriculography and pneumoencephalography: contributions of Dr. Walter E. Dandy. Radiographics 5:553-555, 1985

23. Wellons JC III, Tubbs RS, Leveque JC, Blount JP, Oakes WJ: Choroid plexectomy reduces neurosurgical intervention in patients with hydranencephaly. Pediatr Neurosurg 36:148152,2002

\section{Disclosures}

The authors report no conflict of interest concerning the materials or methods used in this study or the findings specified in this paper.

\section{Author Contributions}

Conception and design: Blitz, Rigamonti. Acquisition of data: Blitz. Analysis and interpretation of data: Blitz, Ahmed. Drafting the article: Blitz, Ahmed. Critically revising the article: all authors. Reviewed submitted version of manuscript: all authors. Approved the final version of the manuscript on behalf of all authors: Blitz.

\section{Supplemental Information \\ Previous Presentations}

This work was presented in part at the annual meeting of the International Society for Hydrocephalus and Cerebrospinal Fluid Disorders held in Bristol, UK, in September 2014.

\section{Correspondence}

Ari M. Blitz: Johns Hopkins Hospital, Baltimore, MD. ablitz1@ jhmi.edu. 